Ming-ming Song*, Yu-min Xie, Bo Song, Zheng-liang Xue*, Nan Nie, Chun-lin Hu and Run-sheng $\mathrm{Xu}$

\title{
The Microstructure and Property of the Heat Affected zone in C-Mn Steel Treated by Rare Earth
}

https://doi.org/10.1515/htmp-2017-0175

Received November 26, 2017; accepted March 20, 2018

\begin{abstract}
The microstructures and impact properties of the heat affected zone (HAZ) in steel treated by rare earth (RE) under different welding processes were discussed. The effect of $\mathrm{Al}$ on the impact properties of the HAZ in RE treated steel was analyzed. It finds that when the welding $t_{8 / 5}$ is smaller than $111 \mathrm{~s}$, the main microstructure in steels is bainite/widmanstatten. The impact toughness of the HAZ is lower than that of the steel matrix. When $t_{8 / 5}$ is more than $250 \mathrm{~s}$, the microstructure is mainly acicular ferrite (AF) in the steel treated by $\mathrm{RE}$, and the impact toughness of HAZ is obviously improved. Even under the welding processing with $t_{8 / 5}$ about $600 \mathrm{~s}$ in RE treated steel can still obtain a lot of AF. While in the steel killed by $\mathrm{Al}$ and treated by $\mathrm{RE}$, the main microstructure is parallel cluster of bainite/widmanstatten, and the impact toughness of HAZ is significantly lower than that of low$\mathrm{Al} \mathrm{RE}$ treated steel. Al can deteriorate the optimizing of RE treatment on HAZ.
\end{abstract}

Keywords: steel, Al, rare earth, inclusion, acicular ferrite

\footnotetext{
*Corresponding authors: Ming-ming Song:

E-mail: smma987@163.com, Zheng-liang Xue:

E-mail:1073271906@qq.com, The State Key Laboratory of Refractories and Metallurgy, Wuhan University of Science and Technology, Wuhan, China; Key Laboratory for Ferrous Metallurgy and Resources Utilization of Ministry of Education, Wuhan University of Science and Technology, Wuhan, China Yu-min Xie, The State Key Laboratory of Refractories and Metallurgy, Wuhan University of Science and Technology, Wuhan, China

Bo Song, School of Metallurgical and Ecological Engineering, University of Science and Technology Beijing, Beijing, China Nan Nie, The State Key Laboratory of Refractories and Metallurgy, Wuhan University of Science and Technology, Wuhan, China Chun-lin Hu, Long Products Business division of Maanshan Iron and Steel Co. LTD, Masteel Design \& Research Institute Co.,Ltd., Maanshan, China

Run-sheng $\mathrm{Xu}$, The State Key Laboratory of Refractories and Metallurgy, Wuhan University of Science and Technology, Wuhan, China
}

\section{Introduction}

During the welding, the heat affected zone (HAZ) experienced a terrible thermal process, which is very different from ordinary heat treatment $[1,2]$. The microstructure and grain of the HAZ can be obviously roughened after the welding process, especially in the process of large heat input welding [3]. Acicular ferrite (AF) nucleated on tiny dispersed nonmetallic inclusion within the austenite grain can optimize the microstructure of the HAZ to a large extent $[4,5]$. The laths of AF have a chaotic nature which can result in retardation for crack propagation in steel. It can meliorate the toughness of HAZ obviously without reducing the strength. Therefore, the steel toughness increases with the increasing of AF [6-8].

It is well-known that rare earth (RE) inclusion can promote the formation of $\mathrm{AF}$ in the $\mathrm{HAZ}$, which is very beneficial to the toughness of the steel $[9,10]$. However, the application and research about the AF have been widely carried out in the field of the steel containing Ti, $\mathrm{Mg}$ and $\mathrm{Zr}$, etc. An appropriate deoxidation of molten steel is often required before the addition of RE [11]. Aluminum is one of the most frequently used deoxidizing elements in steelmaking. However, there is little research on the effect of aluminum deoxidation on the formation of $\mathrm{AF}$ in the steel treated by RE. In order to determine the effect of aluminum deoxidation on the microstructure of the HAZ after the welding process in the steel treated by RE, the impact property and microstructure of welding HAZ in different C-Mn steels under different welding processes were studied. The present study has a great reference meaning for RE application in the welding process.

\section{Experimental}

About $25 \mathrm{~kg}$ raw materials were melted in a vacuum induction furnace. The contents of $\mathrm{C}, \mathrm{Si}, \mathrm{Mn}, \mathrm{P}, \mathrm{S}, \mathrm{Al}$ and $\mathrm{RE}$ in the molten steel were adjusted when the raw materials melted completely. After insulated for some time at $1600^{\circ} \mathrm{C}$, the melt was cast into a steel mold and cooled to room temperature by air. Then the obtained ingots were 
held for $90 \mathrm{~min}$ at $1200^{\circ} \mathrm{C}$ to make the composition homogenized. After that the ingots were forged into rods, size of $\emptyset 15 \mathrm{~mm}$. The forging process started at $1200^{\circ} \mathrm{C}$ and finished when the temperature decreased to $900^{\circ} \mathrm{C}$. The rods were air-cooled from $900^{\circ} \mathrm{C}$ to room temperature after the forging. Table 1 shows the chemical compositions of the obtained steels. Steel No.1 is an untreated reference sample. Steel No.2 was treated by a certain amount of RE La and Ce. Steel No.3 was deoxidized by a little of Al before the addition of RE Ce. T.O means the total content of oxygen in the experimental steels, which was obtained by middle infrared spectroscopy.

Samples were picked up from the forged rods. They were mechanically ground and polished to make the standard metallographic samples. Scanning electron microscope (SEM) and energy dispersive spectrometer were used to investigate the morphology and composition of the inclusions in three steels. After that samples were etched for a few seconds in $4 \mathrm{vol} \%$ nital to observe the microstructures in steels using an optical microscope (OM).

Samples are processed into size of $10.5 \mathrm{~mm} \times 10.5$ $\mathrm{mm} \times 70 \mathrm{~mm}$. Then they were used to implement the thermal cycles, which happened in the HAZ of the steel plate under different welding processes, using a Gleeble 1500D thermal simulator. The detailed experimental welding thermal cycle parameters are obtained by the two dimensional Rykalin mathematical model to simulate the thermal cycle process of plates with $15 \mathrm{~mm}$ thickness [2, 12]. The specimens were heated to $1350^{\circ} \mathrm{C}$ at $100^{\circ} \mathrm{C} / \mathrm{s}$, and then held for $1 \mathrm{~s}$. The cooling times from $800^{\circ} \mathrm{C}$ to $500^{\circ} \mathrm{C}$ $\left(t_{8 / 5}\right)$ were $28 \mathrm{~s}, 111 \mathrm{~s}, 250 \mathrm{~s}$ and $445 \mathrm{~s}$, to simulate the different welding heat inputs. The welding thermal cycle curves are shown in Figure 1.

After the simulated welding processes, specimens were machined into size of $10 \mathrm{~mm} \times 10 \mathrm{~mm} \times 55 \mathrm{~mm}$ for the standard Charpy "V" notch test, and then subjected to impact tests at room temperature on a drop weight impact tester (JB-30B series).

The metallographic observation and "V" notch for Charpy test of HAZ were fixed near the monitoring thermocouple in order to reduce the error resulting from uneven cooling rate, relatively.

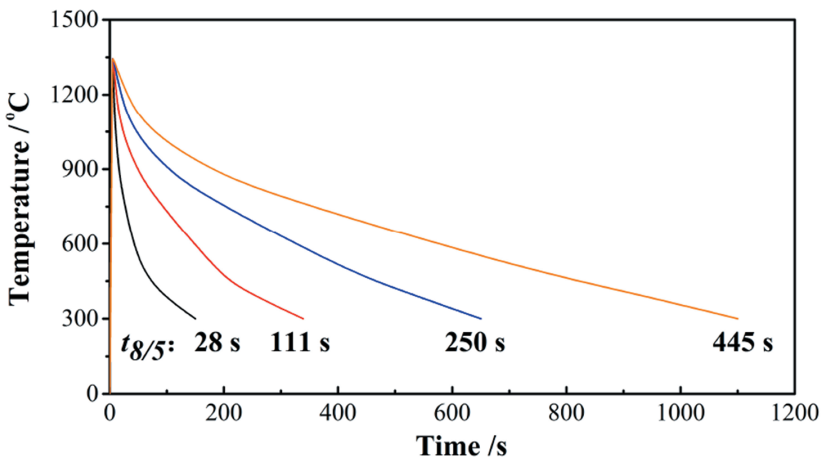

Figure 1: The temperature variation during the simulating thermal cycle in steel.

\section{Results and discussions}

\section{Microstructures}

The forged microstructures in the matrix of three steels are fine granular ferrite and dispersed pearlite. There is little difference among the three steels. The main microstructure is granular ferrite and a small amount of pearlite. And the pearlite is dotted in granular ferrites, as shown in Figure 2. The size of granular ferrite in three steels is very small.

The influence of welding $t_{8 / 5}$ on the microstructure of $\mathrm{HAZ}$ in three steels is shown in Figure 3. When $t_{8 / 5}$ is $28 \mathrm{~s}$, the difference of the microstructures in the HAZ of three steels is little. The main microstructure is bainite/widmanstatten (B/W) as shown in Figure 3(a), (e) and (i). With the increase of the welding $t_{8 / 5}$, the microstructure of the HAZ in three steels changes obviously. When $t_{8 / 5}$ is $111 \mathrm{~s}, 250 \mathrm{~s}$ and $445 \mathrm{~s}$, the microstructure in steel No.1 is mainly grain boundary ferrite (GBF) and parallel bundles of bainite/widmanstatten, and a small amount of pearlite. The longer the welding $t_{8 / 5}$, the greater the size of the GBF and bainite/widmanstatten in the HAZ, as shown in Figure 3(b), (c) and (d). There is little AF in steel No.1 obviously under four welding processes. In steel No.2 treated by RE, the main microstructure is $\mathrm{GBF}$ and $\mathrm{AF}$. Unlike the steel No.1, the content of AF in the HAZ of

Table 1: The chemical composition of the experimental steels/mass $\%$.

\begin{tabular}{lrrrrrrrrr}
\hline Steel & C & Si & Mn & P & S & Al & T.0 & RE & Fe \\
\hline No.1 & 0.13 & 0.31 & 1.30 & 0.015 & 0.008 & $<0.005$ & 0.0025 & - & Bal. \\
No.2 & 0.12 & 0.28 & 1.27 & 0.017 & 0.002 & $<0.005$ & 0.0015 & 0.021 & Bal. \\
No.3 & 0.12 & 0.29 & 1.27 & 0.016 & 0.002 & 0.028 & 0.0015 & 0.018 & Bal. \\
\hline
\end{tabular}

*Steel No.2 and No.3 are treated by La-Ce and Ce, respectively. 

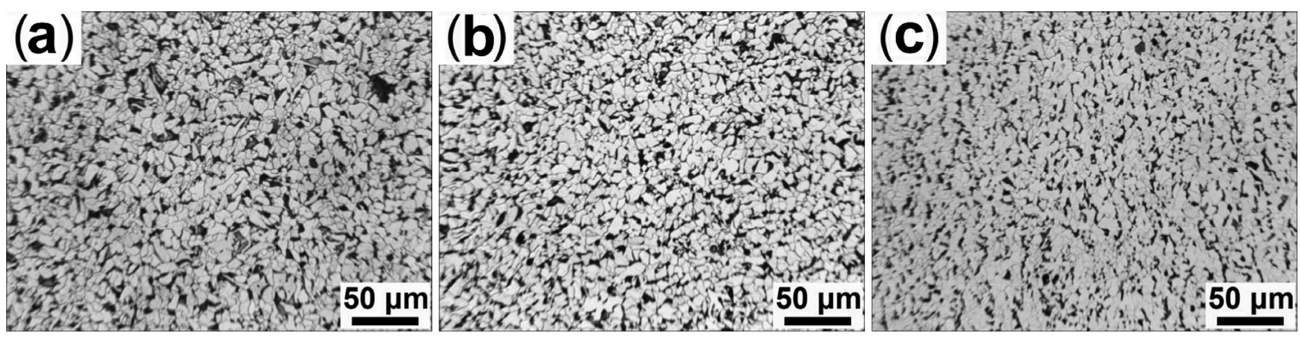

Figure 2: The forged microstructures in three steels, (a) steel No.1; (b) steel No.2; (c) steel No.3.

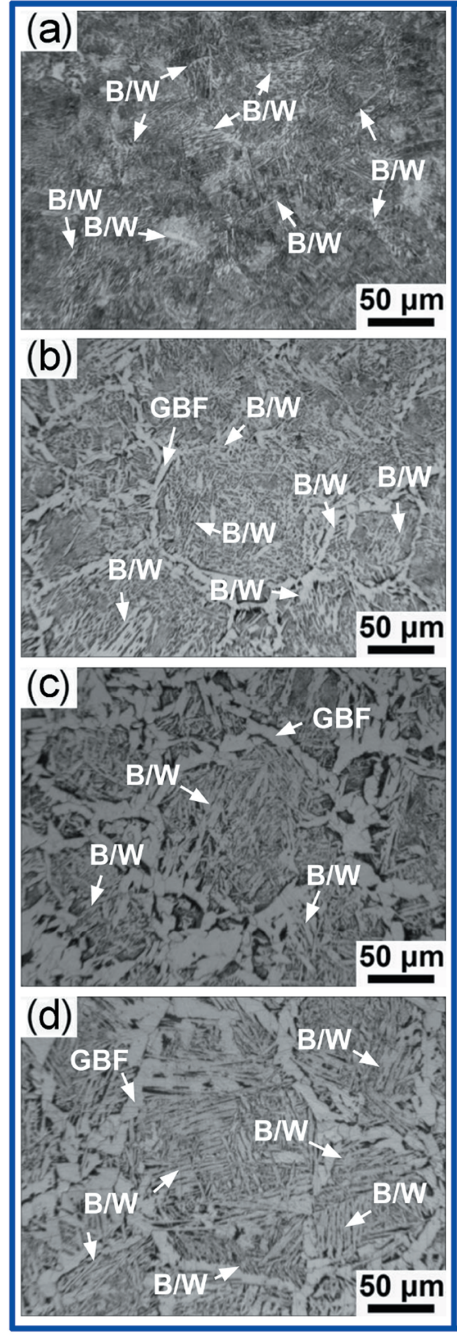

steel No.1

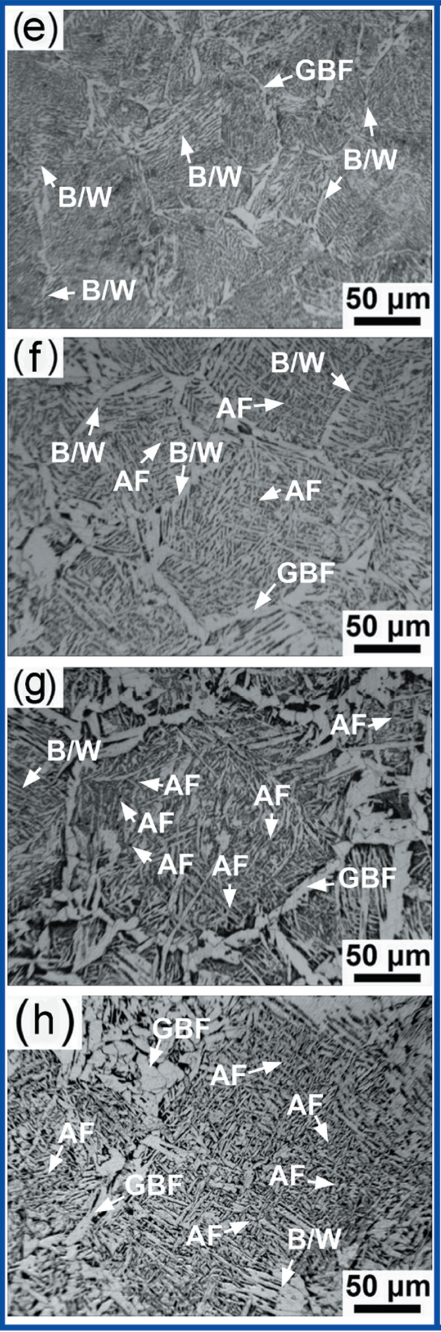

steel No.2

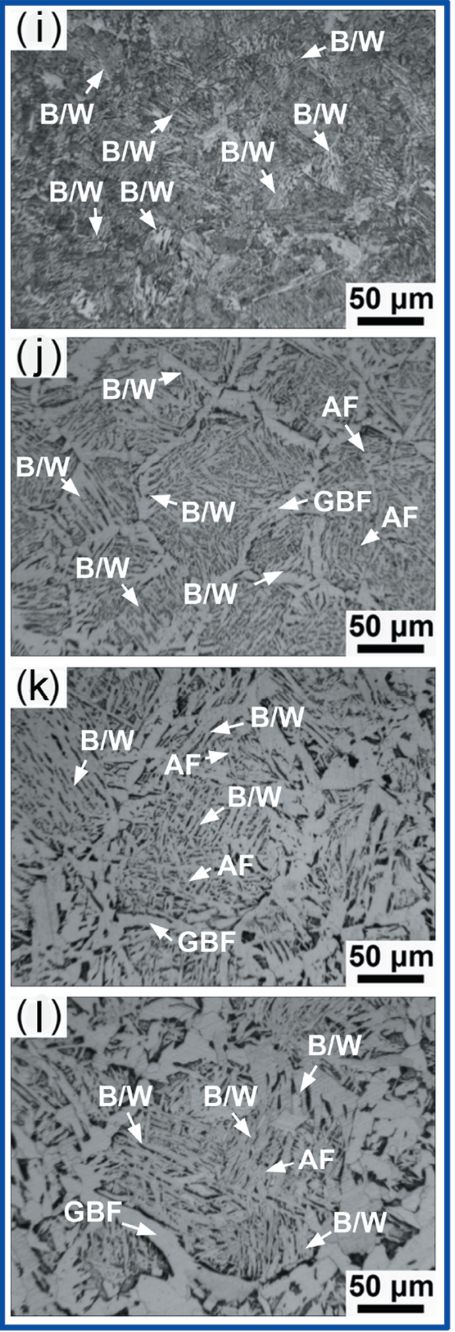

steel No.3

Figure 3: Effect of $t_{8 / 5}$ on the variation of microstructure in the heat affected zone of three steels, (a, e and i) $t_{8 / 5}=28 \mathrm{~s}$; (b, f and j) $t_{8 / 5}=111 \mathrm{~s}$; (c, g and $\mathrm{k}$ ) $t_{8 / 5}=250 \mathrm{~s} ;(\mathrm{d}, \mathrm{h}$ and $\mathrm{l}) t_{8 / 5}=445 \mathrm{~s}$.

steel No.2 is obviously increased. Especially when $t_{8 / 5}$ increase to $250 \mathrm{~s}$ and $445 \mathrm{~s}$, as shown in Figure 3(f), (g) and (h). When the welding $t_{8 / 5}$ is larger relatively, the treatment of $\mathrm{RE}$ can produce more $\mathrm{AF}$ in steel No.2. It means that the addition of RE in C-Mn steel can promote the formation of AF in HAZ. In steel No.3 killed by $\mathrm{Al}$, the microstructure is more or less the same as steel No.1. There is only a small amount of AF within the grain. 
The content of AF in the HAZ of steel No.3 is significantly less than that in steel No.2 under the corresponding sample, as shown in Figure 3(j), (k) and (l).

\section{Inclusion}

Composition, size and quantity of the inclusions have an important influence on the formation of $\mathrm{AF}[13,14]$. The morphology and composition of the typical inclusions in three steels are obtained using the SEM and energy disperse spectrometer, as shown in Figure 4. Figure 4(a) shows the main inclusion is MnS in steel No.1 without the addition of RE. After RE ( $\mathrm{La}$ and $\mathrm{Ce}$ ) added, the inclusion changed into (La,Ce)-O-S in steel No.2, the morphology and energy spectra were shown in Figure 4 (b). While in steel No.3, which first killed by Al then treated by $\mathrm{RE} \mathrm{Ce}$, the main inclusion are $\mathrm{Ce}-\mathrm{S}$ and $\mathrm{Ce}$ Al-O, as shown in Figure 4(c). In steel No.2 and No.3 the $\mathrm{RE}$ containing inclusion is not deformed or broken, the $\mathrm{RE}$ is still spherical after the forging process.

The stable nonmetallic inclusion presented in steel was analyzed by the calculation of phase diagram method and the actual Scheil-Gulliver model calculation was fulfilled by computer software FactSage 7.0 (FactSage(TM) Copyright (c) 1976-2015 Thermfact and GTT-Technologies), based on the principle of minimum free energy $[15,16]$. The result was shown in Figure 5. It can be seen that the main inclusion in steel No.1 is MnS and small amount of Mn-Si-Al-O inclusion. In steel No.2 the main inclusion is
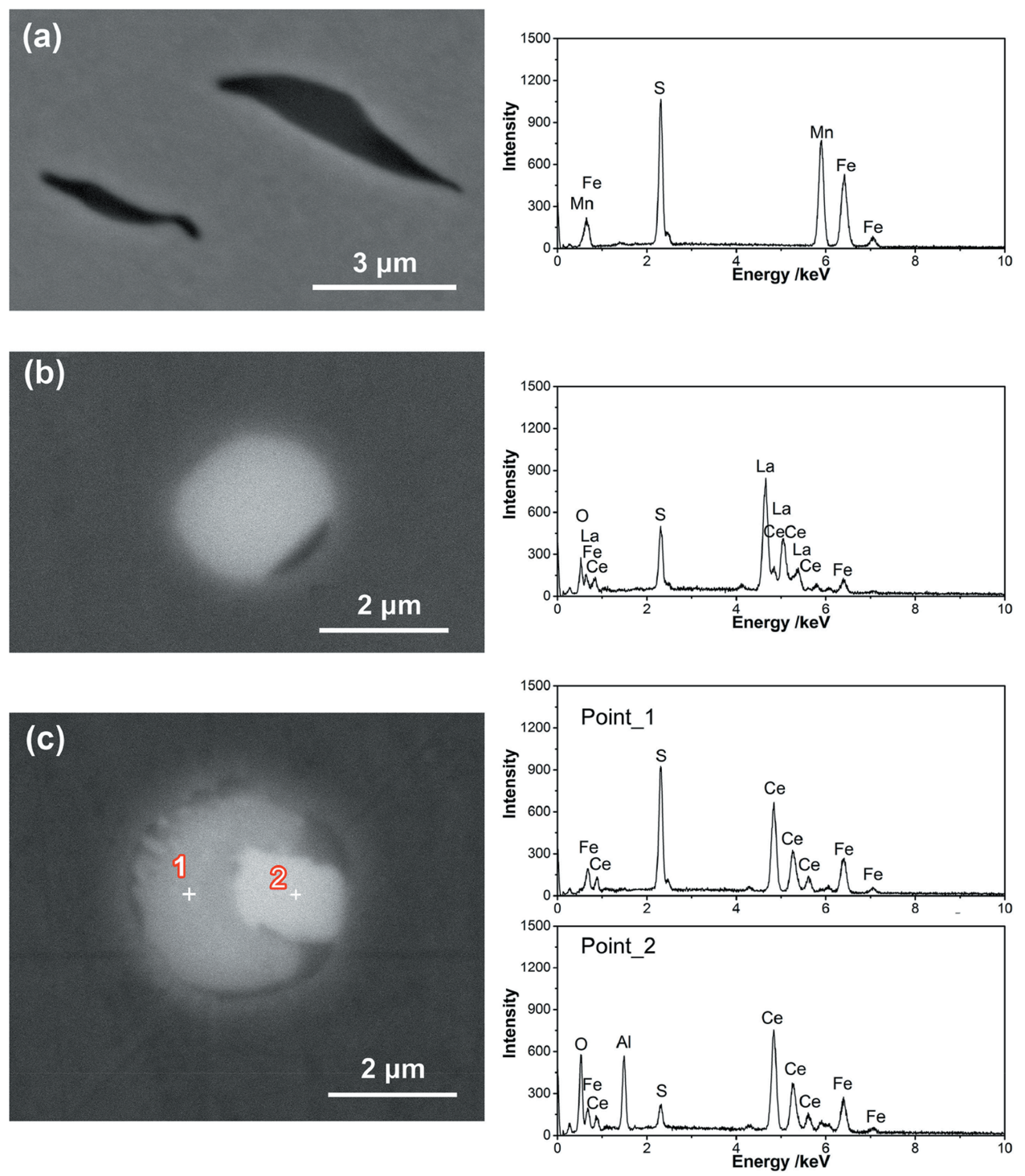

Figure 4: The morphology and composition of the inclusions in the experimental steels, (a) steel No.1; (b) steel No.2; (c) steel No.3. 

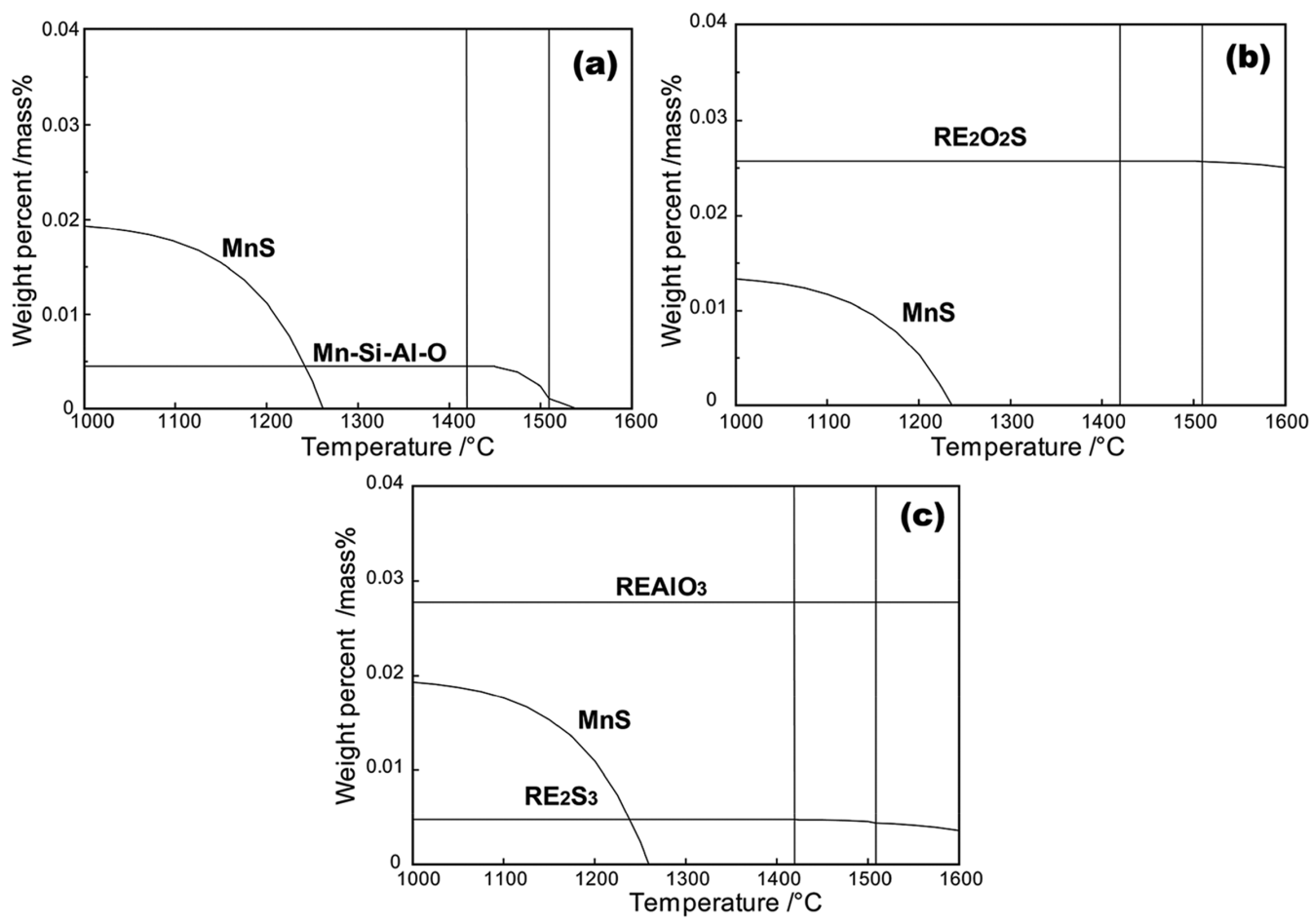

Figure 5: Calculated chemical composition of inclusions in steels, (a) steel No.1; (b) steel No.2; (c) steel No.3.

(La,Ce $)_{2} \mathrm{O}_{2} \mathrm{~S}$ and some $\mathrm{MnS}$. For steel No.3 $\mathrm{CeAlO}_{3}$ and $\mathrm{MnS}$ are the main inclusions, in addition there is a little of $\mathrm{Ce}_{2} \mathrm{~S}_{3}$. So, it can be concluded that aluminum deoxidization has a great influence on the composition of inclusion in $\mathrm{RE}$ treated steel. It can change the inclusion from $\mathrm{RE}_{2} \mathrm{O}_{2} \mathrm{~S}$ to $\mathrm{REAlO}_{3}$ and $\mathrm{RE}_{2} \mathrm{~S}_{3}$.

The nucleation site of ferrite includes grain boundary and intragranular inclusions. The amount of inclusion and the ability of the inclusion to induce the nucleation of ferrite directly affect the number of the final content of $\mathrm{AF}$ nucleated within the austenite grain. To find out the quantity and size distribution of inclusions in three steels, the samples were mechanically ground and polished to take 60 photos randomly by an OM with a magnification of $\times 1000$. The inclusion quantity and size distributions were analyzed in three steels statistically using the image processing software Image J (Image J 4.7v, Wayne Rasband, National Institutes of Health, USA.). The statistical result shows that the difference of the number densities of inclusion is not very much between steel No.2 and No.3, about 203 and 210 per square millimeter, respectively. The inclusion size distribution is shown in Figure 6. It can be found that the mean size of inclusion changed from $2.97 \mu \mathrm{m}$ to $2.75 \mu \mathrm{m}$ after 0.021 mass $\%$ RE added. And the number percent of inclusion smaller than $2 \mu \mathrm{m}$ increased distinctly. When the molten is killed by $\mathrm{Al}$ and treated by $\mathrm{RE}$ in steel No.3, the mean size of the inclusions in the steel is further reduced to

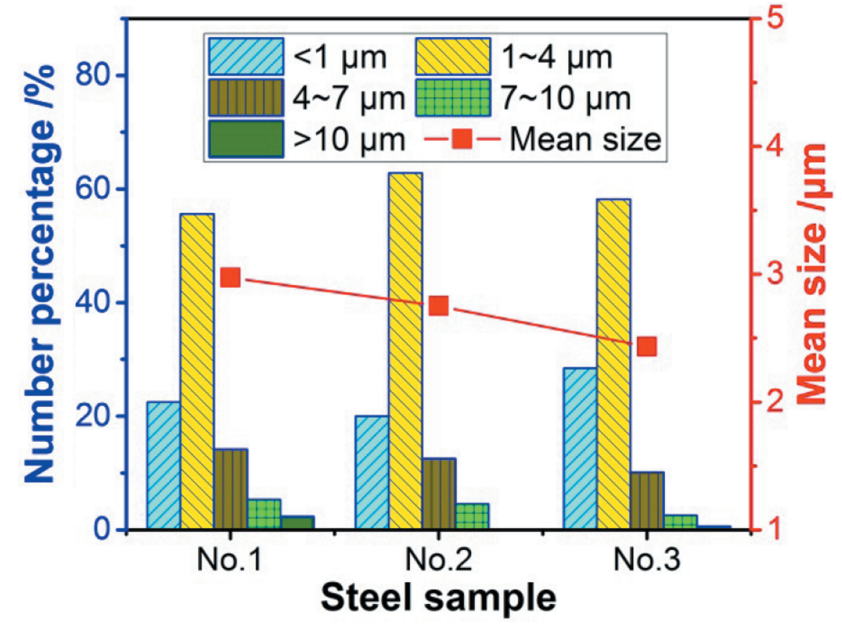

Figure 6: Inclusion size distribution of three steels.

$2.43 \mu \mathrm{m}$. The number percentage of the inclusions smaller than $1 \mu \mathrm{m}$ increased, and the percentage of inclusions greater than $7 \mu \mathrm{m}$ was further reduced compared to that of steel No.2. In general Al deoxidization has a great influence on the size of inclusions in RE treated steel. The size of effective inclusion which can induce the nucleation of $\mathrm{AF}$ are mainly $1 \sim 4 \mu \mathrm{m}$, which has been widely recognized [17]. From Figure 6 it can be easily found that the number percent of inclusion size of $1 \sim 4 \mu \mathrm{m}$ in steel No.3 is less than that in steel No.2, which is adverted to the formation of AF. 


\section{The impact toughness}

The impact toughness of HAZ is a weak control link of the toughness of large welded steel structures. Optimizing the microstructure is one of the most effective methods to improve the impact toughness of the HAZ [18]. It is well-known that widmanstatten and bainite can provide preferential crack-propagation path within a grain, since the widmanstatten and bainite have parallel-like plate structure [19]. Therefore, the impact toughness of steel decreased with the increase of these microstructures. Alternatively, the AF laths nucleate on some inclusions within the grain [20]. The AF laths have a chaotic orientation, which can result in retardation for crack propagation in steel [21]. Thus, the steel impact toughness increases with the increase of $\mathrm{AF}$.

Figure 7 shows the Charpy impact absorbed energy of the HAZs in three steels. It can be seen that in the steel matrix the absorbed energy $\left(A_{k v}\right)$ increased from $193.2 \mathrm{~J}$ to 218.2 J after the addition of RE. While for the steel killed by aluminum, the effect of RE on the impact toughness of the steel matrix is not obvious. In welding HAZ, the absorbed energy of steels first decreased then increased as the increase of welding $t_{8 / 5}$. For steel No.1 and No.2 the worst impact toughness appears when $t_{8 / 5}$ is $111 \mathrm{~s}$, while that come up when $t_{8 / 5}$ is $250 \mathrm{~s}$ in steel No.3. What's more, $\mathrm{RE}$ addition has a great influence on the impact toughness of HAZ at ambient temperature. The impact energy of HAZ in steel No.2 is higher than that in steel No.1 and No. 3 under every welding process correspondingly. When $t_{8 / 5}$ is $445 \mathrm{~s}$, the impact toughness in the HAZ of steel No.2 is more or less the same with the matrix of steel No.1. The impact toughness of steel No.3 after Al deoxidation is lower than that of steel No.1, which is

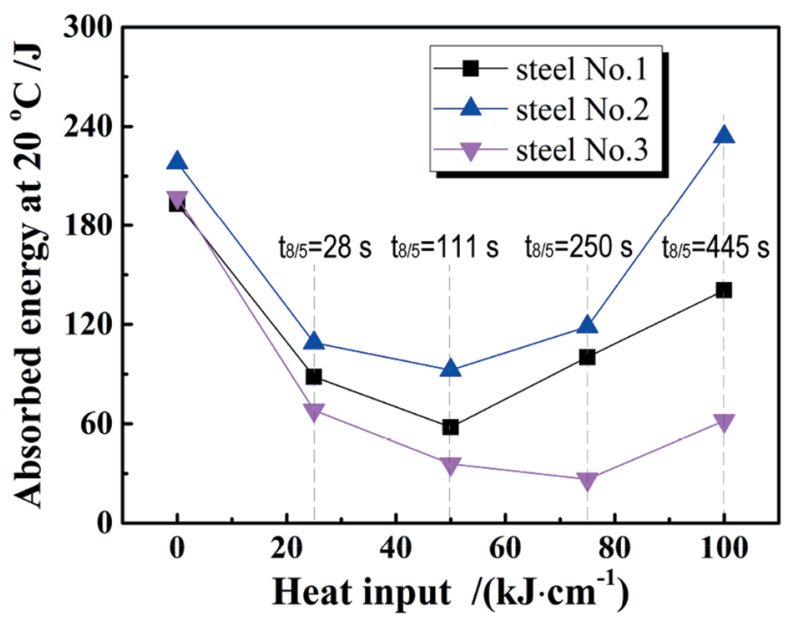

Figure 7: Effects of $t_{8 / 5}$ on the impact toughness of steel. obviously weakened the optimization effect of RE treatment on the impact toughness of HAZ.

When the welding $t_{8 / 5}$ is $28 \mathrm{~s}$ and $111 \mathrm{~s}$, the main microstructure of the steels is bainite/widmanstatten, which decreases the impact toughness of HAZ significantly. However, when $t_{8 / 5}$ increases to $250 \mathrm{~s}$ and $445 \mathrm{~s}$, the impact toughness of HAZ in two steels are enlarged as the appearance of $\mathrm{AF}$ and the decrease of bainite/widmanstatten. When $t_{8 / 5}$ is long ( $>250 \mathrm{~s}$ ), especially when $t_{8 / 5}$ is $445 \mathrm{~s}$, the impact toughness of HAZ in steel No.2 is greater than that of the steel No.1 and No.3. This is attributed to the fact that there is more AF in the HAZ of steel No.2.

From above, it can be seen that RE treatment can improved the performance of the welding $\mathrm{HAZ}$ via optimizing the microstructure. Further increased the $t_{8 / 5}$ to $600 \mathrm{~s}$, there is still a large number of AF formed in the HAZ, as shown in Figure 8. The microstructure of HAZ can be still optimized. It can deduce that RE has a great ability to improved the welding performance of steel.

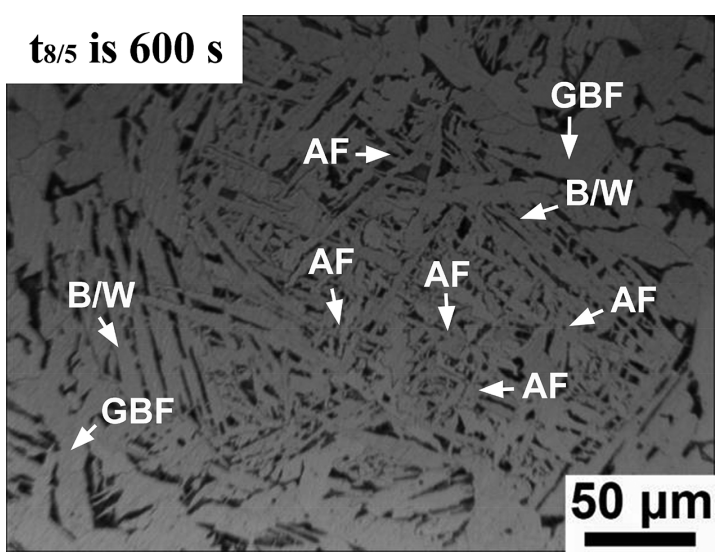

Figure 8: The microstructure of the heat affected zone in steel No.2 after the welding process with $t_{8 / 5}$ is $600 \mathrm{~s}$.

\section{The formation of AF}

The high resolution micrograph of the nucleation of $\mathrm{AF}$ on the surface of typical effective inclusion in RE treated steel No.2 is shown in Figure 9. It can be seen that the effective inclusion which can induce the formation of $\mathrm{AF}$ is the complex inclusion of $\mathrm{RE}_{2} \mathrm{O}_{2} \mathrm{~S}$ and MnS.

From Figure 5 it can be found that $\mathrm{MnS}$ is precipitated in the austenite temperature range. When there are some high melting point fine inclusion particles in the austenitic grain, $\mathrm{MnS}$ can precipitate around the particle easily. The diffusion coefficient of Mn atom in austenite is shown in Figure 10. Mn atom has a relatively larger diffusion coefficient within the formation temperature range of $\mathrm{MnS}$. 


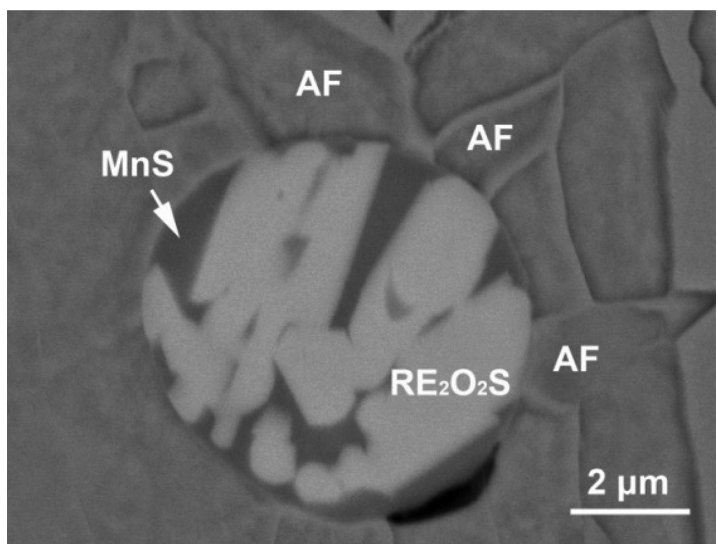

Figure 9: Acicular ferrite formation on rare earth inclusion in HAZ of steel No.2.

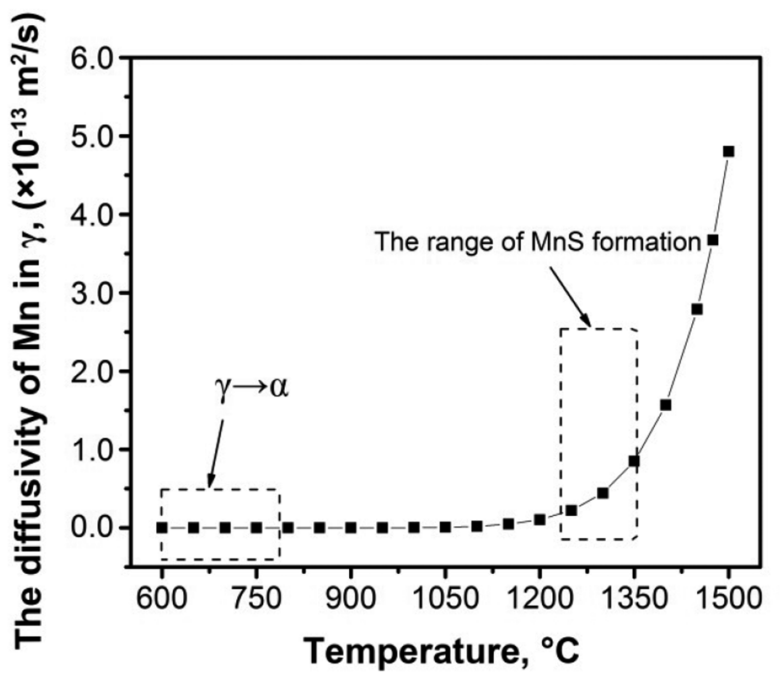

Figure 10: The diffusion coefficient of $\mathrm{Mn}$ elements in austenite at different temperatures.

During the continuous cooling process of welding, Mn atomic diffusion ability and diffusion time are not sufficient, which results in the content reduction of Mn atoms near the inclusion [6]. Moreover, the Mn atoms far from the inclusion cannot spread quickly enough to homogenize the concentration of $\mathrm{Mn}$ atoms during the continuous cooling process. It can generate a Mn depletion zone adjacent to the inclusion in base metal. This can explain the formation of AF in the welding $\mathrm{HAZ}$ of steel No.2 and No.3. But why is there no AF in steel No.1 and the number of AF in steel No.2 is more than that in steel No.3? This is related to the crystal orientation between $\alpha$-Fe and the inclusions in three experimental steels $[10,22]$. According to the two phases' grain orientation relationship under the heterogeneous nucleation process, Bramfitt proposed the principle of two-dimensional misfit [23]. Table 2 lists the lattice misfit between the main inclusions and $\alpha$ - $\mathrm{Fe}$ in three steels. The lattice misfit of $\mathrm{RE}_{2} \mathrm{O}_{2} \mathrm{~S}$ and $\mathrm{RE}_{2} \mathrm{~S}_{3}$ is very small. The misfit between $\mathrm{REAlO}_{3}$ and $\alpha$-Fe is very big. So $\mathrm{RE}_{2} \mathrm{O}_{2} \mathrm{~S}$ and $\mathrm{RE}_{2} \mathrm{~S}_{3}$ in steel have more validity than $\mathrm{REAlO}_{3}$ to induce the formation of AF. In steel No.3, the main inclusion is $\mathrm{REAlO}_{3}$, there is only a little of $\mathrm{RE}_{2} \mathrm{~S}_{3}$. The lack of a large number of effective inclusions is the reason for the low content of AF in steel No.3. The calculation result is consistent well with the as-cast microstructure results found in three specimens, correspondingly.

Apart from the nucleus variation between steel No.2 and No.3, dissolved $\mathrm{Al}$ element can decrease the austenite region and increase the $\mathrm{A}_{3}$ temperature, which can raise the transition temperature of $\gamma \rightarrow \alpha$. It is good for the nucleation of GBF and bainite/widmanstatten. This is not conducive to the formation of $\mathrm{AF}$ in the $\mathrm{HAZ}$ of the $\mathrm{Al}$ killed steel treated by RE.

\section{Conclusions}

In this paper, the influences of welding $t_{8 / 5}$ on the microstructure and property of the HAZ in the steel treated by $\mathrm{RE}$ were discussed. The change of inclusion in steel with different composition was analyzed. The conclusions are as follows:

(1) The main inclusions in C-Mn steel were changed from $\mathrm{MnS}+\mathrm{Mn}-\mathrm{Si}$-Al-O in steel No.1 to $\mathrm{La}_{2} \mathrm{O}_{2} \mathrm{~S}+\mathrm{MnS}$ after $\mathrm{La}$ addition in steel No.2 and then transformed into $\mathrm{LaAlO}_{3}+\mathrm{La}_{2} \mathrm{~S}_{3}+\mathrm{MnS}$ when the content of $\mathrm{Al}$ increased in steel No.3.

(2) The $t_{8 / 5}$ has a great influence on the microstructure in C-Mn steel treated by RE. When $t_{8 / 5}$ is $28 \mathrm{~s}$, the mainly microstructure in the HAZ is bainite/widmanstatten. When $t_{8 / 5}$ is $250 \mathrm{~s}$ and $445 \mathrm{~s}$, there is a lot of $\mathrm{AF}$ in the HAZ.

(3) As the $t_{8 / 5}$ increases, the impact toughness at room temperature of the HAZ first decreases and then increases in C-Mn steel treated by RE. When the $t_{8 / 5}$ is $111 \mathrm{~s}$, the HAZ has the worst impact toughness at room temperature. When $t_{8 / 5}$ increase to $445 \mathrm{~s}$, the impact toughness of the HAZ in RE treated steel is more or less the same with that of the steel matrix without RE treatment.

(4) RE treatment has a great influence on the microstructure of the HAZ in C-Mn steel. After the RE treatment, the HAZ can obtain a lot of AF even under the higher welding $t_{8 / 5}$ as long as $600 \mathrm{~s}$ in C-Mn steel. Al deoxidation is not conducive to obtain AF in the HAZ of the steel treated by RE. 
Table 2: Misfit values between particle constituent phases and ferrite.

\begin{tabular}{|c|c|c|c|c|}
\hline Compound & Crystal system & Lattice parameter, $\mathrm{nm}$ & Planar parallelism & Misfit, \% \\
\hline $\mathrm{LaAlO}_{3}$ & Cubic & $a=0.3807$ & $\begin{array}{l}(100)_{\alpha} / /(100)_{\text {inclusion }},[100]_{\alpha} / /[100]_{\text {inclusion }} \\
(100)_{\alpha} / /(100)_{\text {inclusion }},[110]_{\alpha} / /[100]_{\text {inclusion }}\end{array}$ & $\begin{array}{l}32.8 \dagger \\
15.3 \ddagger\end{array}$ \\
\hline $\mathrm{CeAlO}_{3}$ & Tetragonal & $\begin{array}{l}a=0.3760 \\
c=0.3790\end{array}$ & $(100)_{\alpha} / /(001)_{\text {inclusion, }}[100]_{\alpha} / /[110]_{\text {inclusion }}$ & $7.3 \ddagger$ \\
\hline $\mathrm{La}_{2} \mathrm{~S}_{3}$ & Cubic & $a=0.8616$ & $\begin{array}{l}(111)_{\alpha} / /(111)_{\text {inclusion, }}[110]_{\alpha} / /[110]_{\text {inclusion }} \\
(100)_{\alpha} / /(100)_{\text {inclusion, }},[100]_{\alpha} / / /[110]_{\text {inclusion }}\end{array}$ & $\begin{array}{l}0.2 \dagger \\
6.3 \ddagger\end{array}$ \\
\hline $\mathrm{Ce}_{2} \mathrm{~S}_{3}$ & Cubic & $a=0.8749$ & $\begin{array}{l}(111)_{\alpha} / /(111)_{\text {inclusion, }},[110]_{\alpha} / /[110]_{\text {inclusion }} \\
(100)_{\alpha} / /(100)_{\text {inclusion }},[100]_{\alpha} / /[110]_{\text {inclusion }}\end{array}$ & $\begin{array}{l}1.7 \dagger \\
7.9 \ddagger\end{array}$ \\
\hline $\mathrm{La}_{2} \mathrm{O}_{2} \mathrm{~S}$ & Hсp & $\begin{array}{l}a=0.4051 \\
c=0.6943\end{array}$ & $(111)_{\alpha} / /(0001)_{\text {inclusion }},[110]_{\alpha} / /[11 \overline{2} 0]_{\text {inclusion }}$ & $0.1 \dagger$ \\
\hline $\mathrm{Ce}_{2} \mathrm{O}_{2} \mathrm{~S}$ & Hсp & $\begin{array}{l}a=0.3975 \\
c=0.6826\end{array}$ & $(111)_{\alpha} / /(0001)_{\text {inclusion }},[110]_{\alpha} / /[11 \overline{2} 0]_{\text {inclusion }}$ & $1.9 \dagger$ \\
\hline MnS & Cubic & $a=0.5230$ & $\begin{array}{l}(100)_{\alpha} / /(100)_{\text {inclusion }},[100]_{\alpha} / /[100]_{\text {inclusion }} \\
(100)_{\alpha} / /(100)_{\text {inclusion }},[110]_{\alpha} / /[100]_{\text {inclusion }}\end{array}$ & $\begin{array}{r}29.0 \dagger \\
8.8 \ddagger\end{array}$ \\
\hline
\end{tabular}

*Lattice parameter $\alpha-\mathrm{Fe}=0.28665 \mathrm{~nm}$.

tLow index orientation relationship between ferrite and nucleating substrate.

¥Bain orientation relationship between ferrite and nucleating substrate

Acknowledgements: The authors are grateful for the support of the National Natural Science Foundations of China (NSFC) (grant nos. 51604198, 51474163 and 51274269), the Wuhan University of Science and Technology (WUST) Backbone Training Project of Scientific and Technological (grant no. 2017xz001) and the Open Fund of Key Laboratory for Ferrous Metallurgy and Resources Utilization of Ministry of Education (grant no. FMRUlab17-6).

Funding: The work is financially supported by National Natural Science Foundations of China, Grant Number: 51804229, Hubei Province Natural Science Foundations, Grant Number: 2018CFB306, Open Fund of Key Laboratory for Ferrous Metallurgy and Resources Utilization of Ministry of Education, Grant Number: FMRUlab17-6, Wuhan University of Science and Technology (WUST) Backbone Training Project of Scientific and Technological, Grant Number: 2017xz001.

\section{References}

[1] S.H. Zheng, Q.S. Wu, Q.Y. Huang, S.J. Liu and Y.Y. Han, Fusion Eng. Des., 86 (2011) 2616-2619.

[2] J. Hu, L.X. Du, J.J. Wang and C.R. Gao, Mater. Sci. Eng., 577 (2013) 161-168.

[3] G. Spanos, R.W. Fonda, R.A. Vandermeer and A. Matuszrski, Metall. Mater. Trans., 26 (1995) 3277-3293.

[4] Y. Li, X.L. Wan, W.Y. Lu, A.A. Shirzadi, O. Isayev, O. Hress and K.M. Wu, Mater. Sci. Eng., 659 (2016) 179-187.

[5] X.L. Wan, K.M. Wu, G. Huang, K.C. Nune and Y. Li, Sci. Technol. Weld. Joining, 21 (2016) 295-302.
[6] Y.H. Hou, W. Zheng, Z.H. Wu, G.Q. Li, N. Moelans, M.X. Guo and B.S. Khan, Acta Mater., 118 (2016) 8-16.

[7] L.Y. Xu, J. Yang, R.Z. Wang, Y.N. Wang and W.L. Wang, Metall. Mater. Trans., 47 (2016) 3354-3364.

[8] X.B. Li, Y. Min, C.J. Liu and M.F. Jiang, Mater. Sci. Technol., 32 (2016) 454-462.

[9] B. Wen and B. Song, Steel Res. Int., 83 (2012) 487-495.

[10] M.M. Song, B. Song, S.H. Zhang, Z.L. Xue, Z.B. Yang and R.S. Xu, ISIJ Int., 57 (2017) 1261-1267.

[11] L.M. Wang, Q. Lin, L.J. Yue, L. Liu, F. Guo and F.M. Wang, J. Alloys Compd., 451 (2008) 534-537.

[12] M.H. Shi, P. Zhang, C. Wang and F.X. Zhu, ISIJ Int., 54 (2014) 932-937.

[13] Y. Kang, S. Jeong, J.H. Kang and C. Lee, Metall. Mater. Trans., 47 (2016) 2842-2854.

[14] J.H. Shim, Y.J. Oh, J.Y. Suh, Y.W. Cho, J.D. Shim, J.S. Byun and D.N. Lee, Acta Mater., 49 (2001) 2115-2122.

[15] C.H. Chang, I.H. Jung, S.C. Park, H.S. Kim and H.G. Lee, Ironmaking Steelmaking., 32 (2005) 251-257.

[16] H.S. Kim, H.G. Lee and K.S. Oh, Metall. Mater. Trans., 32 (2001) 1519-1525.

[17] M. Lee, N. Kang, S. Liu and K. Cho, Sci. Technol. Weld. Joining, 21 (2016) 711-719.

[18] W.L. Costin, O. Lavigne and A. Kotousov, Mater. Sci. Eng., 663 (2016) 193-203.

[19] D.S. Sarma, A.V. Karasev and P.G. Jönsson, ISIJ Int., 49 (2009) 1063-1074.

[20] D. Loder and S.K. Michelic, Mater. Sci. Technol., 33 (2017) 162-171.

[21] B. Zhou, G. Li, X. Wan, Y. Li and K. Wu, Met. Mater. Int., 22 (2016) 267-275.

[22] M.M. Song, B. Song, W.B. Xin, G.L. Sun, G.Y. Song and C.L. Hu, Ironmaking Steelmaking, 42 (2015) 594-599.

[23] B.L. Bramfitt, Metall. Trans., 1 (1970) 1987-1995. 